\title{
Size effects in magnetotransport in sol-gel grown nanostructured manganites
}

\author{
N. A. Shah • P. S. Solanki • Ashish Ravalia • \\ D. G. Kuberkar
}

Received: 15 January 2014 / Accepted: 4 March 2014/Published online: 19 March 2014

(c) The Author(s) 2014. This article is published with open access at Springerlink.com

\begin{abstract}
We report the results of the studies on polycrystalline nanostructured $\mathrm{La}_{0.7} \mathrm{~Pb}_{0.3} \mathrm{MnO}_{3}$ (LPMO) manganites synthesized using sol-gel method employing metal acetate precursor route. Interestingly, it is observed that crystallite size decreases with increase in sintering temperature while microscopic investigations reveal the second grain growth in all the samples. A correlation between the grain morphology and secondary grain growth with the transport and magnetotransport in LPMO manganites has been established. Observation of large temperature sensitivity $(\sim-28.29 \% / \mathrm{K} @ 0 \mathrm{~T} ;>300 \mathrm{~K})$ and field sensitivity ( -48.70\%/T@0.2 T; $5 \mathrm{~K})$ in the samples sintered at higher temperature $\left(\sim 1150{ }^{\circ} \mathrm{C}\right)$ has been understood in the light of observed secondary grain growth in the form of nanosized grains over the surface of primary grains.
\end{abstract}

Keywords Size effect - Nanostructure - Manganites . Field sensitivity

\section{Introduction}

Several 3d-metal oxide-based materials exhibit variety of interesting and interrelated phenomena including high- $T_{\mathrm{C}}$ superconductivity (HTSC) in cuprates, colossal magnetoresistance (CMR) in manganites, high spin polarizability of conduction electrons in $\mathrm{CrO}_{2}, \mathrm{Fe}_{3} \mathrm{O}_{4}$, etc. and

N. A. Shah $(\bowtie)$

Department of Electronics, Saurashtra University,

Rajkot 360005, India

e-mail: snikesh@yahoo.com

P. S. Solanki - A. Ravalia - D. G. Kuberkar Department of Physics, Saurashtra University, Rajkot 360005, India ferromagnetism in diluted magnetic semiconductors (DMS). All of these compounds exhibit strong correlations between spin, charge, orbital and lattice degrees of freedom (Urban et al. 2004; Rivas et al. 2000; Yuan et al. 2001). It is well established that a well-defined linkage between the theoretical predictions and experimental findings exists in all of them leading to well-known CMR effect in manganites (Jin et al. 1994), giant thermal expansion (Ibarra et al. 1995), isotopic effect (Zhao et al. 1996) and charge ordering in manganites (Doshi et al. 2011). Various theoretical aspects such as double exchange mechanism (Zener 1951), spin-phonon coupling (Millis et al. 1995) and percolated phase segregated regions (Uehara et al. 1999) have been extensively studied in these compounds. Studies on mixed valent manganites in various form such as polycrystalline bulk (Doshi et al. 2009), nanostructures (Kuberkar et al. 2012), bulk composites (Stoyanova-Ivanova et al. 2011), thin films (Solanki et al. 2011), multilayers (Vachhani et al. 2011), thin film composites (Cheng and Wang 2007) and heterostructures (Khachar et al. 2012) have been reported which shows their application potential in various devices.

Nanophasic $\mathrm{La}_{0.7} \mathrm{Sr}_{0.3} \mathrm{MnO}_{3}$ (LSMO) manganites synthesized by sol-gel have been studied for the modification in transport and magnetic behavior (Gaur and Varma 2006). Also, intrinsic and extrinsic magnetoresistance (MR) behavior of nanophasic $\mathrm{La}_{0.7} \mathrm{Ca}_{0.3} \mathrm{MnO}_{3}$ (LCMO) has been found to depend strongly on particle size (Siwach et al. 2006). Among various chemical methods of synthesizing nanostructured manganites, namely, co-precipitation (Solanki et al. 2010), pechini method (Pechini 1967), urea gel complex method (Vazquez-Vazquez et al. 1998), citric acid-ethylene diamine gel route (Mahesh et al. 1996), molten alkali metal nitrate flux (Luo et al. 2003), amorphous citrate method (Courty et al. 1973) and PVA-based 
chemical synthesis route (Pandya et al. 2001), it is seen that sol-gel (Kuberkar et al. 2012) is the most simple and costeffective method for obtaining uniformly distributed manganite nanoparticles.

In order to understand various physical properties of nanostructured manganites and their thin films, few proposed mechanisms and theories have been reported. LopezQuintela et al. (2003) have studied the intergranular magnetoresistance (IMR) in sol-gel-grown nanostructured $\mathrm{La}_{2 /}$ ${ }_{3} \mathrm{Ca}_{1 / 3} \mathrm{MnO}_{3}$ manganites. They have explained that magnetization of nanoparticles decreases with increase in surface/volume ratio in the context of core-shell model wherein nanoparticles composed of an inner core and particle boundaries are considered as outer shells. They argued that with increase in particle size, intrinsic magnetism remains unchanged in inner core, while in outer shells different magnetic states are expected mainly due to oxygen vacancies and superficial stress (Lopez-Quintela et al. 2003). They have also used electrostatic blockade model for carriers between grains to explain the unexpected low-temperature resistivity upturn using which authors have found the blocking energy values for charge carriers of nanostructured manganites (Lopez-Quintela et al. 2003). Similar low-temperature resistivity behavior, observed in $\mathrm{La}_{0.5} \mathrm{Pr}_{0.2} \mathrm{Ba}_{0.3} \mathrm{MnO}_{3}$ manganite films, has been discussed by Rana et al. (2005) which has been attributed to the electron-electron scattering mechanism due to coulombic interactions between charge carriers. Similar theory has been discussed for low-temperature resistivity behavior for the $\mathrm{La}_{0.7} \mathrm{~Pb}_{0.3} \mathrm{MnO}_{3}$ manganite-based chemically grown thin films (Solanki et al. 2011). Other reports are also available on the various theoretical aspects considered to understand the transport properties of manganites (Rana et al. 2004). Recently, Cossu et al. (2013) have performed the first principle calculations to investigate $\mathrm{LaMnO}_{3}$ / $\mathrm{SrTiO}_{3}$ superlattice.

Till date, several research reports are available on the particle size-dependent changes in the transport and magnetic properties of mixed valent manganites (Gaur and Varma 2006; Siwach et al. 2006) but very few studies are reported on the temperature and field sensitivity in manganite-based thin films (Markna et al. 2006; Parmar et al. 2006; Kataria et al. 2013).

From application point of view, it is necessary to investigate the manganite materials having appreciably large MR at or near room temperature. Occurrence of phase transitions and magnetic ordering at low temperatures under relatively large applied fields has become a bottle neck for the suitability of manganites for device applications. LPMO is a unique substituted rare earth manganite having large MR under relatively low applied field and ferromagnetic ground state at room temperature (Mahendiran et al. 1995). In this communication, we report the results of the studies on the magnetotransport properties and field and temperature sensitivity in nanostructured $\mathrm{La}_{0.7} \mathrm{~Pb}_{0.3} \mathrm{MnO}_{3}$ (LPMO) manganites. Also, the grain morphology and grain size affect the field and temperature sensitivity in LPMO manganites which has been discussed in the light of size and surface effects.

\section{Experimental details}

Nanostructured polycrystalline bulk $\mathrm{La}_{0.7} \mathrm{~Pb}_{0.3} \mathrm{MnO}_{3}$ (LPMO) manganites were synthesized using low-cost and simple sol-gel method using metal acetate precursor route. Mixing of all the metal acetate precursors (and $\mathrm{Pb}$ in carbonate form) was carried out in a solution of acetic acid and double distilled water having 1:1 volume ratio. Continuous mixing, stirring, heating and drying of the appropriate stoichiometric quantities of the metal acetates of $\mathrm{La}$ and $\mathrm{Mn}$ and $\mathrm{Pb}$-carbonate resulted in clear xerogel form of material. Grinding of the xerogel for $30 \mathrm{~min}$ resulted in a brown-colored powder which was then calcined at $750{ }^{\circ} \mathrm{C}$ for hours. Resultant black powder was subsequently palletized and sintered at different temperatures $\left(1050,1100\right.$ and $\left.1150^{\circ} \mathrm{C}\right)$ in order to obtain the samples with different grain sizes. Hereafter, the samples sintered at 1050,1100 and $1150{ }^{\circ} \mathrm{C}$ temperatures are referred as 1050 , 1100 and 1150 , respectively. XRD measurements were performed to know the structural phases present while AFM micrographs were obtained to study the effect of sintering temperature on the grain morphology and grain size. Resistance and magnetoresistance (MR) measurements performed using $\mathrm{dc}$ four probe method in the temperature range from 2 to $380 \mathrm{~K}$ under 0-9 $\mathrm{T}$ applied magnetic field.

\section{Results and discussion}

XRD patterns of all the LPMO samples sintered at different temperatures in Fig. 1 show the single phasic nature of samples crystallizing in rhombohedral structure having $R$-3C space group (no. 167). Figure 2 shows an enlarged view of most intense (110) and (104) peaks of all the samples indicating higher angle shifting of the peaks with increase in sintering temperature suggesting the decrease in unit cell parameters and cell volume. Obtained cell volume [using Rietveld refinement of the XRD patterns using FULLPROF program (Rodriguez-Carvajal 1990)] (Rietveld fitted XRD pattern of 1050 sample is shown as an inset of Fig. 2) decreases from $0.4158 \mathrm{~nm}^{3}$ (1050) to $0.4093 \mathrm{~nm}^{3}$ (1150). Interestingly, it is observed that with increase in sintering temperature, XRD peak intensity decreases while peak width increases (Figs. 1,2). This results in the decrease in crystallite size (CS) with increase in sintering temperature, which is contrary to the earlier reported studies (Gaur 


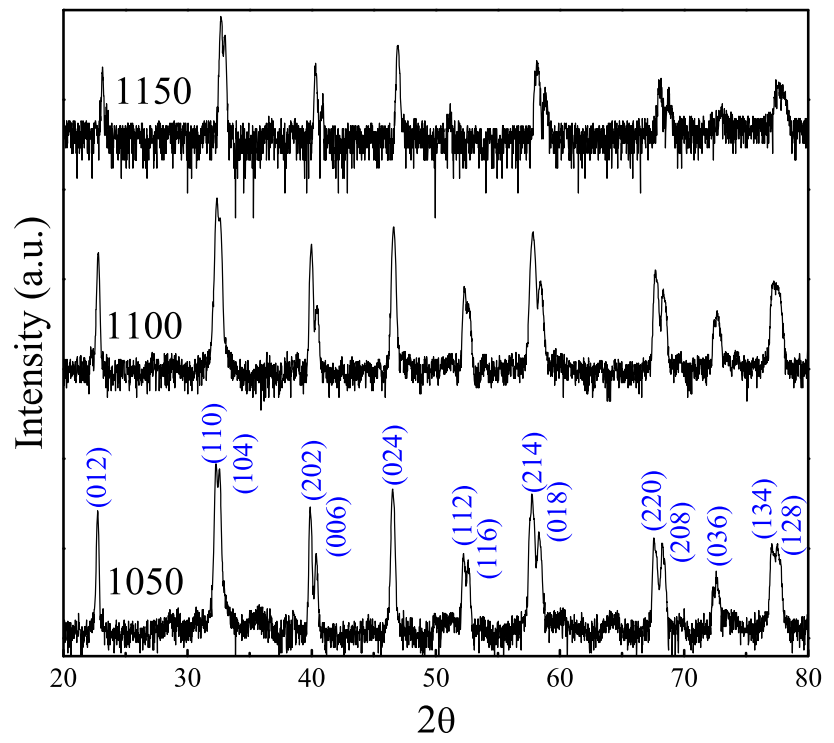

Fig. 1 XRD patterns of $\mathrm{La}_{0.7} \mathrm{~Pb}_{0.3} \mathrm{MnO}_{3}$ manganites sintered at different temperatures. Inset Rietveld fitted XRD pattern of $\mathrm{La}_{0.7} \mathrm{~Pb}_{0.3} \mathrm{MnO}_{3}$ manganite sintered at $1050{ }^{\circ} \mathrm{C}$

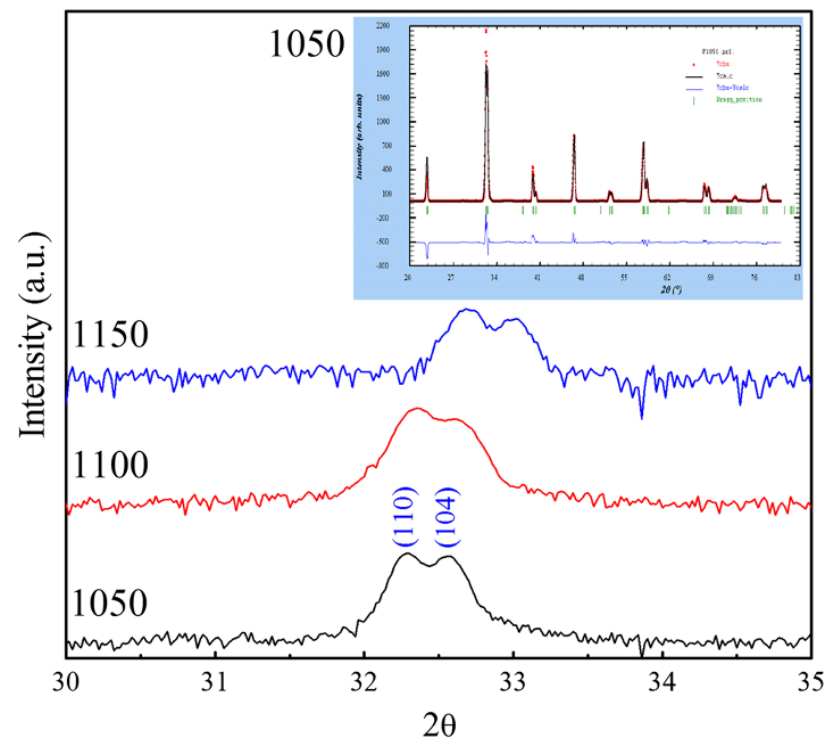

Fig. 2 Enlarged view of (110) and (104) peaks at $2 \theta \sim 32.5^{\circ}$ for $\mathrm{La}_{0.7} \mathrm{~Pb}_{0.3} \mathrm{MnO}_{3}$ manganites sintered at different temperatures

and Varma 2006; Siwach et al. 2006). Calculated values of CS, using Scherer's formula: $\mathrm{CS}=0.9 \lambda / B \cos \theta$, where $\lambda$ is the X-ray wavelength used, $B$ is the peak width (FWHM) and $\theta$ is the Bragg angle, are $20.01 \mathrm{~nm}(1050), 15.29 \mathrm{~nm}$ (1100) and $14.88 \mathrm{~nm}$ (1150). The values of Rietveld-refined $\mathrm{Mn}-\mathrm{O}-\mathrm{Mn}$ bond angles and $\mathrm{Mn}-\mathrm{O}$ bond lengths for all the LPMO samples are listed in Table 1. In Table 1, reported values of $\mathrm{Mn}-\mathrm{O}-\mathrm{Mn}$ bond angle and $\mathrm{Mn}-\mathrm{O}$ bond lengths are also listed for reference purpose (Alonso 1998).

For understanding the sintering temperature-dependent modifications in the grain size and morphology, AFM
Table 1 Values of Mn-O-Mn bond angles, Mn-O bond lengths and differences between the values of average basal and epical Mn-O-Mn bond angles $(\Delta)$ and $\mathrm{Mn}-\mathrm{O}$ bond lengths $(D)$ for nanostructured $\mathrm{La}_{0.7} \mathrm{~Pb}_{0.3} \mathrm{MnO}_{3}$ manganites sintered at different temperatures

\begin{tabular}{|c|c|c|c|c|}
\hline Parameters & $\begin{array}{l}\mathrm{LaMnO}_{3} \\
\text { (Alonso 1998) }\end{array}$ & 1050 & 1100 & 1150 \\
\hline $\mathrm{Mn}-\mathrm{O}_{1}\left(^{\circ}\right)$ & $1.9789(6)$ & $1.969(3)$ & $1.963(2)$ & $1.958(3)$ \\
\hline $\begin{array}{l}\text { Average } \\
\mathrm{Mn}-\mathrm{O}_{2}\left({ }^{\circ}\right)\end{array}$ & 1.9745 (2) & $1.965(2)$ & $1.961(4)$ & $1.957(4)$ \\
\hline$\Delta\left(^{\circ}\right)$ & - & 0.004 & 0.002 & 0.001 \\
\hline $\mathrm{Mn}-\mathrm{O}_{1}-\mathrm{Mn}(\AA)$ & $161.49(1)$ & $162.13(5)$ & $163.82(1)$ & $164.28(4)$ \\
\hline $\mathrm{Mn}-\mathrm{O}_{2}-\mathrm{Mn}(\AA)$ & - & 174.47 (2) & $174.98(3)$ & $175.05(3)$ \\
\hline$D(\AA)$ & - & 12.34 & 11.16 & 10.77 \\
\hline
\end{tabular}

micrographs were obtained for all the nanostructured LPMO samples. Figure 3 shows clear granular nature of the samples evident from the micrographs with grain size increases from $1.0 \mu \mathrm{m}$ (1050) to $1.3 \mu \mathrm{m}(1100)$ and $1.9 \mu \mathrm{m}$ (1150) resulting in the decrease in grain boundary density. It can be seen that, in the samples sintered at $1050{ }^{\circ} \mathrm{C}$, there is a growth of smaller secondary grains over the surface of micron-sized primary grains (Fig. 3). The size of secondary grains decreases from $150 \mathrm{~nm}(1050)$ to $90 \mathrm{~nm}$ (1150) with sintering temperature. It is clear that the secondary grain density and hence connectivity between them increase with the sintering temperature which can be correlated with the decrease in crystallinity and CS (Figs. 1, 2).

The simultaneous effect of grain growth and secondary grain size on the transport properties of sol-gel-grown nanostructured LPMO manganites was understood by performing temperature-dependent resistivity measurements under various applied magnetic fields as shown in Fig. 4. All the samples show metal $(\mathrm{d} \rho / \mathrm{d} T>0)$ to insulator $(\mathrm{d} \rho / \mathrm{d} T<0)$ transition at $T_{\mathrm{P}}$. Resistivity decreases with increase in sintering temperature which can be understood as-with increase in sintering temperature, the primary grain size increases from 1.0 to $1.9 \mu \mathrm{m}$ resulting in the decrease in grain boundary density which consequences in the decrease in scattering of the charge carriers across the grain boundaries and hence decrease in resistivity. Also, resistivity gets suppressed with applied magnetic field leading to negative MR in all the samples which can be ascribed to the field-induced reduction in the magnetic spin scattering of the charge carriers at the grain boundaries and improved magnetic order of the grain boundaries. In addition, $T_{\mathrm{P}}$ increases with increase in sintering temperature as well as with applied field, which can be due to the sintering temperature-induced improved grain boundary nature and field-induced reduction in the non-magnetic phase fraction which significantly support the zener double exchange (ZDE) mechanism and hence enhance the $T_{\mathrm{P}}$. 

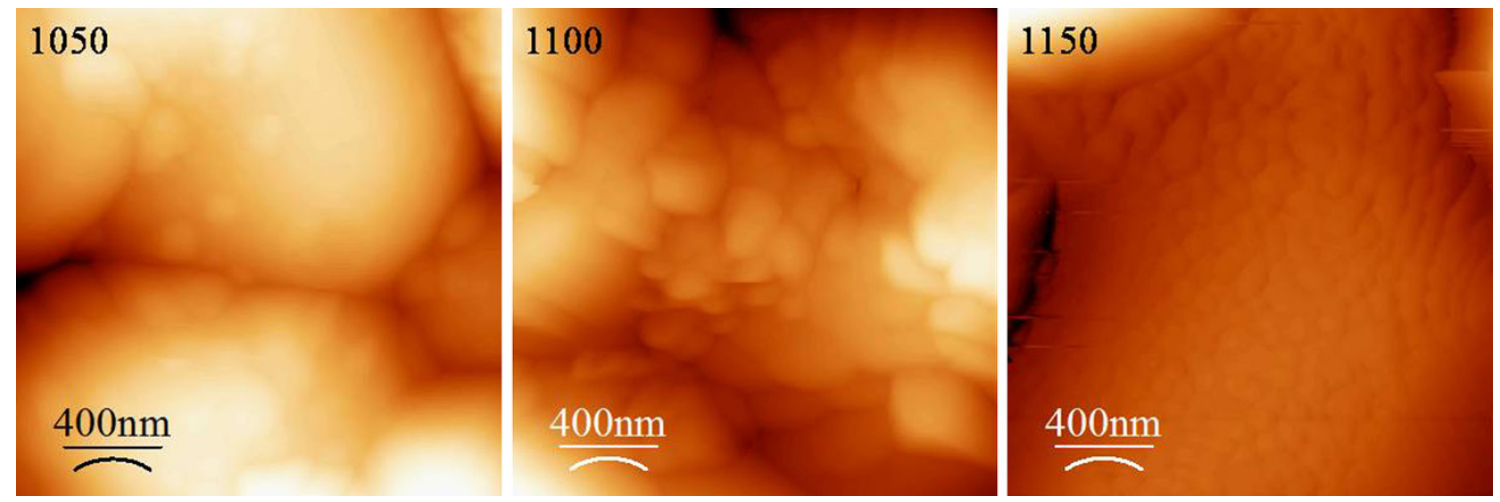

Fig. 3 Microstructural (AFM) images of nanostructured $\mathrm{La}_{0.7} \mathrm{~Pb}_{0.3} \mathrm{MnO}_{3}$ manganites sintered at different temperatures

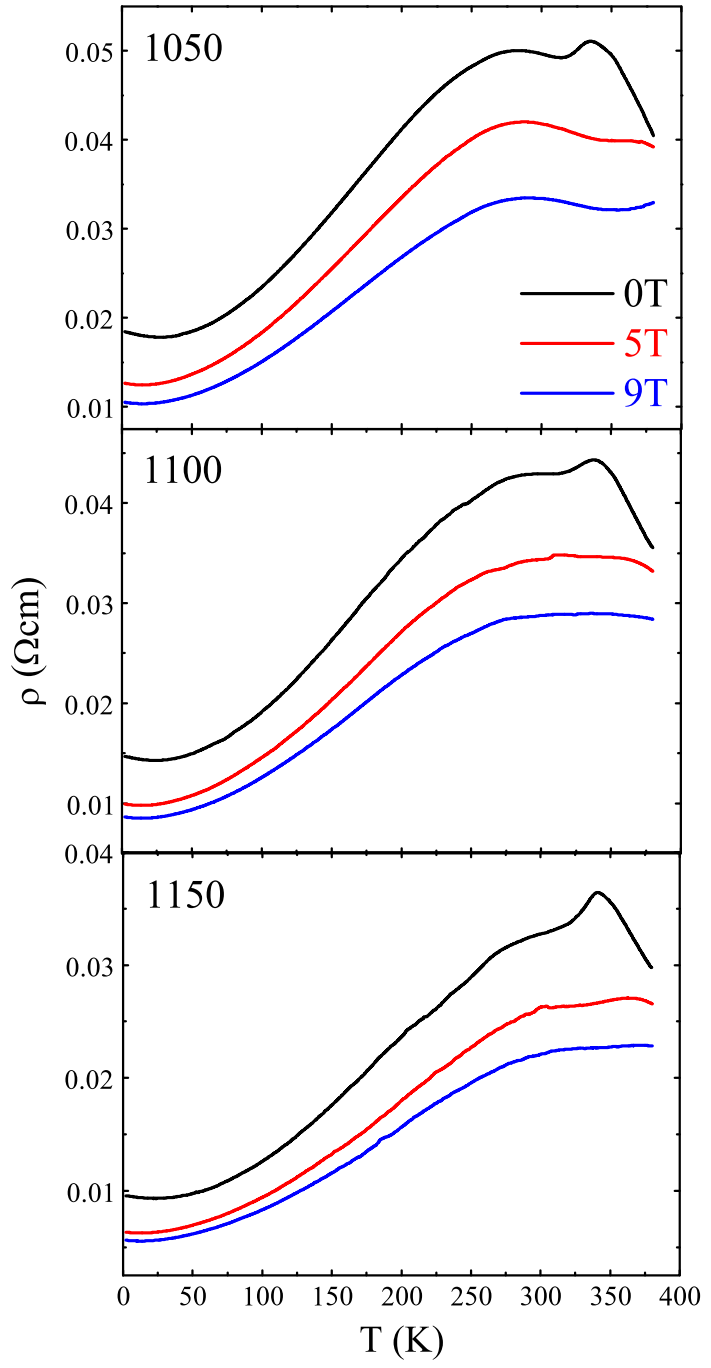

Fig. 4 Resistivity $(\rho)$ vs. temperature $(T)$ plots under 0,5 and $9 \mathrm{~T}$ applied magnetic fields for nanostructured $\mathrm{La}_{0.7} \mathrm{~Pb}_{0.3} \mathrm{MnO}_{3}$ manganites sintered at different temperatures

The effect of decrease in the secondary grain size on the transport in LPMO can be understood as-smaller secondary grain size results in better connectivity between them in higher sintered samples having sharp and ordered grain boundaries which in turn results in the improved charge transport. In addition, the observation of a small hump-like behavior observed at $\sim 300 \mathrm{~K}$ in $\rho-T$ plots of LPMO may be due to the secondary grain growth which can be modified under applied field.

From Table 1, it can be seen that upon the substitution of $\mathrm{Pb}^{2+}$ at $\mathrm{La}^{3+}$ site in $\mathrm{LaMnO}_{3}, \mathrm{Mn}-\mathrm{O}$ bond lengths (both, basal and epical) get reduced while $\mathrm{Mn}-\mathrm{O}-\mathrm{Mn}$ bond angles get increased. With increase in sintering temperature, $\mathrm{Mn}-$ $\mathrm{O}$ bond length decreases while $\mathrm{Mn}-\mathrm{O}-\mathrm{Mn}$ bond angles increase which in turn improve the transfer integral of charge carriers and hence decrease in resistivity and increase in $T_{\mathrm{P}}$. This can also be supported by the $\mathrm{MnO}_{6}$ octahedral distortion which can be quantified by the differences between the Rietveld-refined values of average basal and epical $\mathrm{Mn}-\mathrm{O}-\mathrm{Mn}$ bond angles $(\Delta)$ and $\mathrm{Mn}-\mathrm{O}$ bond lengths $(D)$. As listed in Table 1, values of $\Delta$ and $D$ decrease from 1050 to 1150 indicating the decrease in $\mathrm{MnO}_{6}$ octahedral distortion and improved transport.

MR isotherms $\left(\mathrm{MR}=\left[\left\{\left(\rho_{\mathrm{H}}-\rho_{0}\right) / \rho_{0}\right\} \times 100\right]\right)$ were recorded at $5 \mathrm{~K}$ (to understand the extrinsic contribution to MR) and $300 \mathrm{~K}$ (to study the intrinsic contribution to MR) for all the samples studied. Extrinsic MR is the low-temperature, low-field $(\leq 1 \mathrm{~T})$ MR exhibited by the manganites mainly governed by external parameters such as grain size, grain boundary density, grain boundary nature, temperature history, final sintering/annealing temperature, etc. Intrinsic MR is the MR observed at $\sim T_{\mathrm{P}} / T_{\mathrm{C}}$ under high magnetic field ( $>1 \mathrm{~T}$ ), originating mainly due to the zener double exchange mechanism. Figure 5 shows the MR vs. $\mathrm{H}$ isotherms of all the nanostructured LPMO manganites studied. All the samples exhibit negative MR at 5 and $300 \mathrm{~K}$ which increases with field. At $5 \mathrm{~K}$, on increasing the field, MR continuously increases with large slope (dMR/ $\mathrm{d} H$ ) below $1 \mathrm{~T}$ and smaller slope at higher fields. Lowfield, low-temperature MR (extrinsic MR) can be ascribed to the spin-polarized tunneling (Hwang et al. 1996) or spindependent scattering (Gupta and Sun 1999) across the grain 


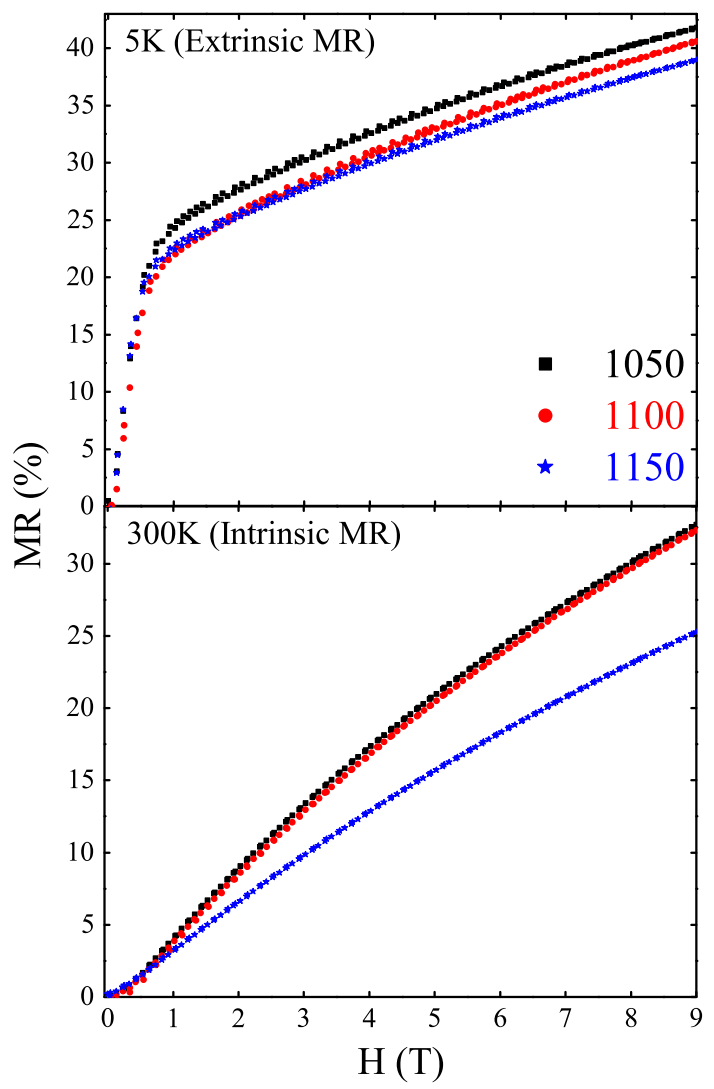

Fig. 5 Field-dependent MR isotherms collected at 5 and $300 \mathrm{~K}$ for nanostructured $\mathrm{La}_{0.7} \mathrm{~Pb}_{0.3} \mathrm{MnO}_{3}$ manganites sintered at different temperatures

boundaries while high-field, low-temperature MR depends on the reorientation and stiffness of the spins and connectivity between the micron-sized grains and nanostructured secondary grains over the primary grains. At $5 \mathrm{~K}$, large low-field extrinsic MR $\sim 20$ to $25 \%$ is observed which decreases with sintering temperature throughout the field range studied. Similarly, at $300 \mathrm{~K}$, MR decreases from $32.70 \%$ (1050) to $25.26 \%$ (1150) under $9 \mathrm{~T}$. Reduction in MR at 5 and $300 \mathrm{~K}$ with sintering temperature can be understood as-with increase in sintering temperature, grain size increases, grain boundary density decreases and secondary grain connectivity increases leading to the decrease in non-magnetic disordered phase resulting into the total reduction in the field-induced suppression in scattering of the charge carriers and magnetic disorder (i.e. reduction in total field effect) consequence in the decrease in MR with sintering temperature.

To explore the application potential of sol-gel-grown nanostructured LPMO samples, we have calculated the temperature and field sensitivity of resistivity quantified by temperature coefficient of resistance $[\mathrm{TCR}=(1 / R) \times(\mathrm{d} R /$ $\mathrm{d} T) \times 100(\% / \mathrm{K})]$ and field coefficient of resistance $[\mathrm{FCR}=(1 / R) \times(\mathrm{d} R / \mathrm{d} H) \times 100 \quad(\% / \mathrm{T})], \quad$ respectively.

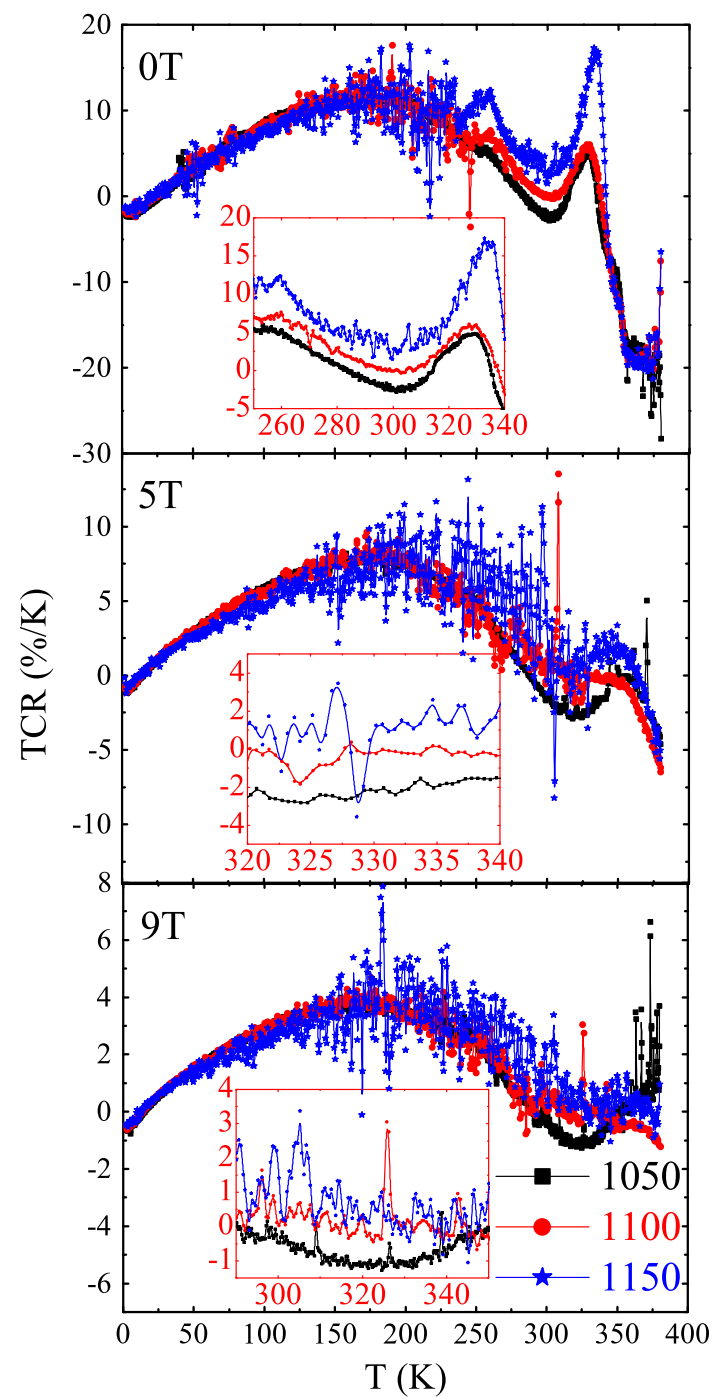

Fig. 6 Variation in temperature sensitivity (TCR) with temperature under 0,5 and $9 \mathrm{~T}$ applied magnetic field for nanostructured $\mathrm{La}_{0.7} \mathrm{~Pb}_{0.3} \mathrm{MnO}_{3}$ manganites sintered at different temperatures. Inset enlarged view of TCR vs. $T$ plots (where fluctuations are less) under 0,5 and $9 \mathrm{~T}$ fields for the clarity purpose

Few reports are available on the field and temperature sensitivities of manganite-based thin films (Parmar et al. 2006; Markna et al. 2006; Kataria et al. 2013) but, for the first time, we report the TCR and FCR studies on nanostructured manganites to understand the effect of surface and nanostructured secondary grain growth. Figure 6 shows the variation in TCR with temperature under various applied fields. All the samples show large fluctuations in sensing the temperature in terms of resistance which may be attributed to the disordered structure of the nanophasic samples (Khachar et al. 2013) and thermal fluctuations of the spins. Overall, it can be seen that with increase in sintering temperature, TCR increases which can be attributed to the large surface area (due to smaller secondary 
grain size) in higher sintered samples and hence large reactivity of the dangling spins of the charge carriers. This also supports the comparatively larger fluctuations in TCR in higher sintered samples, under all the applied fields. With increase in field, TCR decreases mainly due to the field-induced modifications in the surface spin structure. Under $0 \mathrm{~T}$ field, 1150 sample exhibits maximum values of TCR $\sim 17.30$ and $-28.29 \% / \mathrm{K}$ well above room temperature which is useful for practical applications of LPMO manganites. Figure 7 shows the variation in FCR with applied field at 5 and $300 \mathrm{~K}$ for all the nanostructured LPMO samples. At low temperature, where spins are most stable, favoring ferromagnetism and hence able to sense the field change appreciably, large FCR values are observed. No fluctuation has been recorded at low temperature with maximum FCR -42.60 \%/T (1050) under relatively lower applied field $\sim 0.2 \mathrm{~T}$ which increases up to $\sim-48.70 \% / \mathrm{T}$ (1150) under the same field (inset of Fig. 7). Increased field sensitivity of the samples sintered at higher temperatures can be ascribed to the large surface area of the samples having smaller-sized secondary grains. With insignificant fluctuations in FCR at $300 \mathrm{~K}$, overall FCR gets suppressed as compared to that at $5 \mathrm{~K}$, mainly

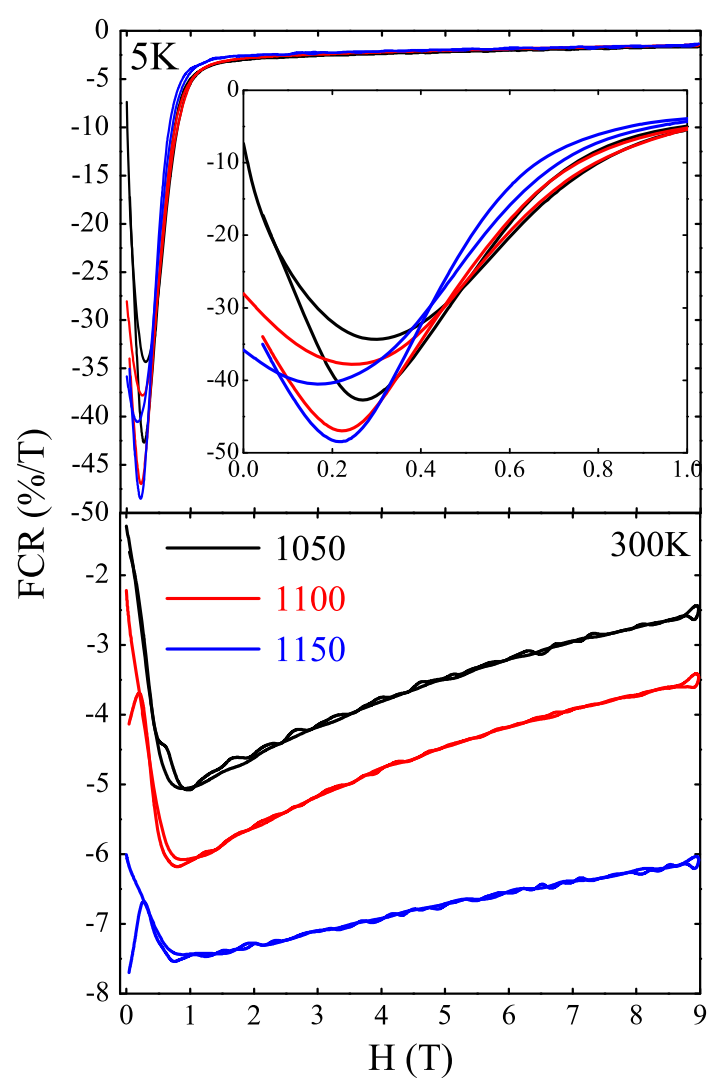

Fig. 7 Variation in field sensitivity (FCR) with field at 5 and $300 \mathrm{~K}$ for nanostructured $\mathrm{La}_{0.7} \mathrm{~Pb}_{0.3} \mathrm{MnO}_{3}$ manganites sintered at different temperatures. Inset enlarge view of FCT vs. $\mathrm{H}$ plots at $5 \mathrm{~K}$ (field range $0-1 \mathrm{~T}$ ) for clarity purpose due to large thermal effects existing at $300 \mathrm{~K}$. By engineering the surface area and designing the grains in these materials, one can achieve large temperature and field sensitivity of the nanostructured manganites.

\section{Conclusions}

In summary, we have successfully synthesized nanostructured $\mathrm{La}_{0.7} \mathrm{~Pb}_{0.3} \mathrm{MnO}_{3}$ (LPMO) manganites using low-cost sol-gel method by employing metal acetate precursor route. Observed decrease in crystallite size has been understood in the context of secondary growth of nanostructured grains over the surface of the micron-sized grains. The transport and MR behaviors have been understood in the light of grain morphology and observed nanostructured secondary grain growth. Improved transport has been correlated with increased grain size, decrease in grain boundary density and compactness and connectivity between the nanostructured grains. MR has been discussed on the basis of intrinsic and extrinsic MR components and its dependence on the microstructural behavior of the samples. Field and temperature sensitivity and its variation with sintering temperature have been ascribed to the large surface area in higher sintered samples due to the presence of nanostructured secondary grain growth over the primary grains.

Acknowledgments Authors thankfully acknowledge Dr. V. Ganesan, UGC-DAE CSR, Indore for providing the experimental facilities for microstructural and transport measurements. Mr. Mohan Gangrade is thankfully acknowledged for his valuable support in carrying out AFM micrographs and specially detecting secondary grain growth. PSS is thankful to DST, New Delhi for the award of Fast Track Young Scientist (File No. SR/FTP/PS-138/2010).

Open Access This article is distributed under the terms of the Creative Commons Attribution License which permits any use, distribution, and reproduction in any medium, provided the original author(s) and the source are credited.

\section{References}

Alonso JA (1998) Non-stoichiometry and properties of mixed valent manganites. Philos Trans R Soc Lond 356:1617-1634

Cheng Z, Wang X (2007) Room temperature magnetic-field manipulation of electrical polarization in multiferroic thin film composite $\mathrm{BiFeO}_{3} / \mathrm{La}_{2 / 3} \mathrm{Ca}_{1 / 3} \mathrm{MnO}_{3}$. Phys Rev B 75(172406): $1-4$

Cossu F, Singh N, Schwingenschlogl U (2013) High mobility half metallicity in the $\left(\mathrm{LaMnO}_{3}\right)_{2} /\left(\mathrm{SrTiO}_{3}\right)_{8}$ superlattice. Appl Phys Lett 102:042401

Courty P, Ajot H, Marcilly C (1973) Mixed oxides or a solid solution form very divided obtained by thermal decomposition of precursor amorphous. Powder Technol 7:21-38

Doshi RR, Solanki PS, Krishna PSR, Das A, Kuberkar DG (2009) Magnetic phase coexistence in $\mathrm{Tb}^{3+}-$ and $\mathrm{Sr}^{2+}$-doped 
$\mathrm{La}_{0.7} \mathrm{Ca}_{0.3} \mathrm{MnO}_{3}$ manganite: a temperature-dependent neutron diffraction. J Magn Magn Mater 321:3285-3289

Doshi RR, Solanki PS, Khachar U, Kuberkar DG, Krishna PSR, Banerjee A, Chaddah P (2011) First order paramagneticferromagnetic phase transition in $\mathrm{Tb}^{3+}$ doped $\mathrm{La}_{0.5} \mathrm{Ca}_{0.5} \mathrm{MnO}_{3}$ manganite. Phys B 406:4031-4034

Gaur A, Varma GD (2006) Sintering temperature effect on electrical transport and magnetoresistance of nanophasic $\mathrm{La}_{0.7} \mathrm{Sr}_{0.3} \mathrm{MnO}_{3}$. J Phys Condens Matter 18:8837-8846

Gupta A, Sun JZ (1999) Spin polarized transport and magnetoresistance in magnetic oxides. J Magn Magn Mater 200:24-43

Hwang HY, Cheong SW, Ong ON, Batlogg B (1996) Spin-polarized intergrain tunneling in $\mathrm{La}_{2} / 3 \mathrm{Sr}_{1} / 3 \mathrm{MnO}_{3}$. Phys Rev Lett 77:2041-2044

Ibarra MR, Algarabel PA, Marquina C, Blasco J, Garcia J (1995) Large magnetovolume effect in yttrium doped $\mathrm{La}-\mathrm{Ca}-\mathrm{Mn}-\mathrm{O}$ perovskite. Phys Rev Lett 75:3541-3544

Jin S, Tiefel TH, McCormack M, Fastnacht RA, Ramesh R, Chen LH (1994) Thousandfold change in resistivity in magnetoresistive La-Ca-Mn-O films. Science 264:413-415

Kataria B, Solanki PS, Khachar U, Vagadia M, Ravalia A, Keshvani MJ, Trivedi P, Venkateshwarlu D, Ganesan V, Asokan K, Shah NA, Kuberkar DG (2013) Role of strain and microstructure in chemical solution deposited $\mathrm{La}_{0.7} \mathrm{~Pb}_{0.3} \mathrm{MnO}_{3}$ manganite films: thickness dependent swift heavy ions irradiation studies. Radiat Phys Chem 85:173-178

Khachar U, Solanki PS, Choudhary RJ, Phase DM, Ganesan V, Kuberkar DG (2012) Current-voltage characteristics of PLD grown manganite based $\mathrm{ZnO} / \mathrm{La}_{0.5} \operatorname{Pr}_{0.2} \mathrm{Sr}_{0.3} \mathrm{MnO}_{3} /$ $\mathrm{SrNb}_{0.002} \mathrm{Ti}_{0.998} \mathrm{O}_{3}$ thin film heterostructure. Solid State Commun 152:34-37

Khachar U, Solanki PS, Choudhary RJ, Phase DM, Kuberkar DG (2013) Positive MR and large temperature-field sensitivity in manganite based heterostructures. J Mater Sci Technol 29:989-994

Kuberkar DG, Doshi RR, Solanki PS, Khachar U, Vagadia M, Ravalia A, Ganesan V (2012) Grain morphology and size disorder effect on the transport and magnetotransport in sol-gel grown nanostructured manganites. Appl Surf Sci 258:9041-9046

Lopez-Quintela MA, Hueso LE, Rivas J, Rivadulla F (2003) Intergranular magnetoresistance in nanomanganites. Nanotechnology 14:212-219

Luo F, Huang YH, Yan CH, Jiang S, Li XH, Wang ZM, Liao CS (2003) Molten alkali metal nitrate flux to well-crystallized and homogeneous $\mathrm{La}_{0.7} \mathrm{Sr}_{0.3} \mathrm{MnO}_{3}$ nanocrystallites. J Magn Magn Mater 260:173-180

Mahendiran R, Mahesh R, Raychaudhuri AK, Rao CNR (1995) Room temperature giant magnetoresistance in $\mathrm{La}_{1-\mathrm{x}} \mathrm{Pb}_{\mathrm{x}} \mathrm{MnO}_{3}$. J Phys D Appl Phys 28:1743-1745

Mahesh R, Mahendiran R, Raychaudhuri AK, Rao CNR (1996) Effect of particle size on the giant magnetoresistance of $\mathrm{La}_{0.7} \mathrm{Ca}_{0.3} \mathrm{MnO}_{3}$. Appl Phys Lett 68:2291-2293

Markna JH, Parmar RN, Kuberkar DG, Kumar R, Rana DS, Malik SK (2006) Thickness dependent swift heavy ion irradiation effects on electronic transport of $\left(\mathrm{La}_{0.5} \mathrm{Pr}_{0.2}\right) \mathrm{Ba}_{0.3} \mathrm{MnO}_{3}$ thin films. Appl Phys Lett 88(152503):1-3

Millis AJ, Littlewood PB, Shraiman BI (1995) Double exchange alone does not explain the resistivity of $\mathrm{La}_{1-\mathrm{x}} \mathrm{Sr}_{\mathrm{x}} \mathrm{MnO}_{3}$. Phys Rev Lett 74:5144-5147

Pandya DK, Kashyap SC, Pattanaik GR (2001) Magnetoresistive behavior of $\mathrm{La}_{0.67}\left(\mathrm{Ca}_{0.33-\mathrm{x}} \mathrm{Pb}_{\mathrm{x}}\right) \mathrm{MnO}_{3}$ nanopowders prepared by lower temperature. J Alloys Compd 326:255-259

Parmar RN, Markna JH, Kuberkar DG, Kumar R, Rana DS, Bagve VC, Malik SK (2006) Swift-heavy-ion-irradiation-induced enhancement in electrical conductivity of chemical solution deposited $\mathrm{La}_{0.7} \mathrm{Ba}_{0.3} \mathrm{MnO}_{3}$ thin films. Appl Phys Lett 89(202506): 1-3

Pechini MP (1967) Method of preparing lead and alkaline earth titanates and niobates and coating method using the same to form a capacitor. US Pat. No. 3330697

Rana DS, Thaker CM, Mavani KR, Kuberkar DG, Kundaliya DC, Malik SK (2004) Magnetic and transport properties of $\left(\mathrm{La}_{0.7-2 \mathrm{x}} \mathrm{Eu}_{\mathrm{x}}\right)\left(\mathrm{Ca}_{0.3} \mathrm{Sr}_{\mathrm{x}}\right) \mathrm{MnO}_{3}$ : effect of simultaneous size disorder and carrier density. J Appl Phys 95:4934-4940

Rana DS, Markna JH, Parmar RN, Kuberkar DG, Raychaudhuri P, John J, Malik SK (2005) Low temperature transport anomaly in the magnetoresistive compound $\left(\mathrm{La}_{0.5} \mathrm{Pr}_{0.2}\right) \mathrm{Ba}_{0.3} \mathrm{MnO}_{3}$. Phys Rev B 71:212404

Rivas J, Hueso LE, Fondado A, Rivadulla F, Lopez-Quintela MA (2000) Low field magnetoresistance effects in fine particles of $\mathrm{La}_{0.67} \mathrm{Ca}_{0.33} \mathrm{MnO}_{3}$ perovskites. J Magn Magn Mater 221:57-62

Rodriguez-Carvajal J (1990) FULLPROF: a program for rietveld refinement and pattern matching analysis. In: Abstracts of the satellite meeting on powder diffraction of the $\mathrm{XV}$ congress of the IUCr, Toulouse, France, p 127

Siwach PK, Goutam UK, Srivastava P, Singh HK, Tiwari RS, Srivastava ON (2006) Colossal magnetoresistance study in nanophasic $\mathrm{La}_{0.7} \mathrm{Ca}_{0.3} \mathrm{MnO}_{3}$ manganite. J Phys D Appl Phys 39:14-20

Solanki PS, Doshi RR, Khachar UD, Vagadia MV, Ravalia AB, Kuberkar DG, Shah NA (2010) Structural, microstructural, transport and magnetotransport properties of nanostructured $\mathrm{La}_{0.7} \mathrm{Sr}_{0.3} \mathrm{MnO}_{3}$ manganites synthesized by coprecipitation. J Mater Res 25:1799-1802

Solanki PS, Doshi RR, Khachar UD, Choudhary RJ, Kuberkar DG (2011) Thickness dependent transport and magnetotransport in CSD Grown $\mathrm{La}_{0.7} \mathrm{~Pb}_{0.3} \mathrm{MnO}_{3}$ manganite films. Mater Res Bull 46:1118-1123

Stoyanova-Ivanova AK, Staneva AD, Shoumarova JM, Blagoev BS, Zaleski AJ, Mikli V, Dimitriev YB (2011) Microstructure and superconductivity of bulk BPSCCO/LPMO composite. Philos Mag Lett 91:190-199

Uehara M, Mori S, Chen CH, Cheong SW (1999) Percolative phase separation underlies colossal magnetoresistance in mixed valent manganites. Nature (London) 399:560-563

Urban JJ, Ouyang L, Jo MH, Wang DS, Park H (2004) Synthesis of single crystalline $\mathrm{La}_{1-\mathrm{x}} \mathrm{Ba}_{\mathrm{x}} \mathrm{MnO}_{3}$ nanocubes with adjustable doping levels. Nano Lett 4:1547-1550

Vachhani PS, Solanki PS, Doshi RR, Shah NA, Rayaprol S, Kuberkar DG (2011) Substrate dependent transport and magnetotransport in manganite multilayer. Phys B 406:2270-2272

Vazquez-Vazquez C, Blanco MC, Lopez-Quintela MA, Sanchez RD, Rivas J, Oseroff SB (1998) Characterization of $\mathrm{La}_{0.67} \mathrm{Ca}_{0.33} \mathrm{MnO}_{3}$ particles prepared by the sol-gel route. $\mathrm{J}$ Mater Chem 8:991-1000

Yuan SL, Zhang GQ, Peng G, Tu F, Zeng XY, Liu J, Yang YP, Jiang Y, Tang CQ (2001) Electrical transport and low field magnetoresistance in the series of mixed polycrystals $(1-\mathrm{m}) \mathrm{La}_{2 / 3} \mathrm{Ca}_{1 /}$ ${ }_{3} \mathrm{MnO}_{3}+\mathrm{mLa}_{2 / 3} \mathrm{Ca}_{1 / 3} \mathrm{MnO}_{3}$. J Phys Condens Matter 13:5691-5698

Zener C (1951) Interaction between the d-shells in the transition metals. II. Ferromagnetic compounds of manganese with perovskite structure. Phys Rev 82:403-405

Zhao G, Conder K, Keller H, Muller KA (1996) Giant oxygen isotope shift in the magnetoresistive perovskite $\mathrm{La}_{1-\mathrm{x}} \mathrm{Ca}_{\mathrm{x}} \mathrm{MnO}_{3+\mathrm{y}}$. Nature (London) 381:676-678 